\title{
Morphology and properties of polymer matrix nanocomposites
}

\author{
Salah H.R. Ali ${ }^{1, \star}$, M.K. Bedewy ${ }^{2, \star \star}$, M.A. $\operatorname{Etman}^{3}$, H.A. Khalil ${ }^{4}$, and B.S. Azzam ${ }^{5}$ \\ 1 Engineering and Surface Metrology, National Institute for Standards (NIS), Giza, Egypt \\ 2 Dean of Engineering, Misr Univ. for Science and Technology, 6th of October, Egypt \\ 3 Mechanical Eng. Dept, Al-Ahram Higher Institute for Eng. and Tech., Egypt \\ ${ }^{4}$ Chemistry Lab, National Research Centre (NRC), Dokki, Giza, Egypt \\ 5 Design \& Production Eng., Faculty of Eng., Cairo Univ., Egypt
}

Received: 15 January 2010 / Accepted: 5 March 2010

\begin{abstract}
Carbon nanotubes (CNTs) have become strongly promising nano-particles for developing novel smart polymer matrix nanocomposites to satisfy the ever increasing design requirements of the recent avenues of space industry and other special structural applications. The objective of this paper is to investigate the influence of doped and dispersed CNTs in polymer matrix on its intrinsic properties. Three different types of polymers; polyvinylchloride (PVC), polymethylemethacrylate (PMMA), and polystyrene (PS) were subjected to this experimental investigation. CNTs/polymer matrix composites with a content ratio of CNTs up to $5 \%$ by weight were synthesized in lab. The nanocomposites were then characterized by measuring their mechanical, electrical, and thermal properties. In addition, thermo gravimetric analysis (TGA), Fourier transform infra red spectroscopy (FTIR), and scanning electron microscopy (SEM) were applied, and the results are presented and discussed. It can be generally concluded that both PMMA and PS polymers disclosed much better matching ability and cross linking ability with the interweaving CNTs than the PVC. Both PMMA and PS polymers may thus be nominated for further extension of the investigation to cover a wider range of CNTs content ratios in an endeavour towards searching for maximum specific performance properties of such nanocomposites.
\end{abstract}

Keywords: Nanoscale metrology; CNTs/polymer; characterization; surface morphology; TGA analysis; FTIR spectroscopy; SEM

\section{Introduction}

Composite material, in its basic form, is a heterogeneous combination of two or more materials, differing in form or composition. The combination results in a material that exploits the (mechanical, electrical, thermal and chemical) properties of individual constituents and maximizes specific performance properties of the composite [1]. Carbon nanotubes (CNTs) have proven to be an excellent additive to impart electrical conductivity in polymers at lower loadings, compared to conventional additive materials such as carbon black, chopped carbon fiber, or stainless steel fiber without impairing the other properties $[2,3]$. Their high aspect ratio (about 1000:1) would result in improved mechanical and physical properties [3-5].

This paper aims at synthesizing CNTs/polymer matrix composites using three different types of polymers, namely: polyvinylchloride (PVC), polymethylemethacrylate (PMMA), and polystyrene (PS). Percentile content of CNTs up to $5 \%$ by weight was covered. The effect of CNTs loading on the physical properties of the composites was studied. Thermo gravimetric analysis (TGA), Fourier

^ Correspondence: SalahAli20@yahoo.com

${ }^{\star \star}$ Correspondence: KBedewy@yahoo.com transform infra red spectroscopy (FTIR), and scanning electron microscopy (SEM) metrology techniques were applied on the synthesized CNTs/polymer matrix composites in order to have an insight into their intrinsic properties. The results revealed that both PMMA and PS polymers possess better matching ability and cross linking with the interweaving CNTs than the PVC polymer does. This may highlight the importance of the necessity of conducting more experimental work on both PMMA and PS polymers with wider scope of CNTs loading content ratios to maximize specific performance properties.

\section{Synthesis of NTs/polymer matrix composite}

A prescribed weight of each test polymer (PVC, PMMA, and PS) was dissolved in an appropriate solvent such as Toluene (phenylmethane) using a small magnet bar. A specified amount of CNTs was then weighed and dispersed slowly in exact amount of solute and moulded into thin films having CNTs content ratio by weight up to $5 \%$. The films were then trimmed and cut into small standard test samples whose properties were studied and characterized. Instron universal testing machine was used for measuring the mechanical properties, and the two probes point 


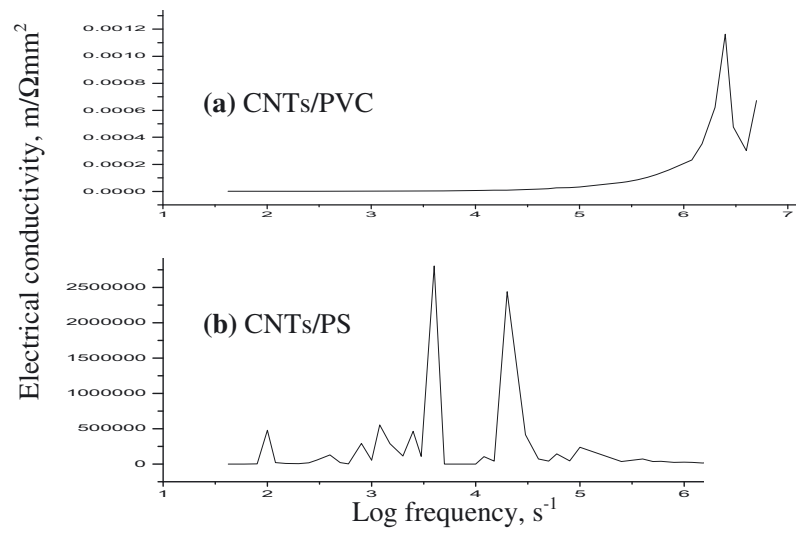

Fig. 1. Electrical conductivity of CNTs/polymer composites.

Table 1. Mechanical properties of CNTs/PVC compared with PVC.

\begin{tabular}{l|ccc}
\hline Material Properties & $\begin{array}{c}\text { Tensile } \\
\text { strength } \\
\text { MPa }\end{array}$ & $\begin{array}{c}\text { Elongation } \\
\text { at break } \\
\%\end{array}$ & $\begin{array}{c}\text { Tensile } \\
\text { modulus } \\
\text { MPa }\end{array}$ \\
\hline CNTs/PVC & 4.35 & 253.1 & 8.35 \\
PVC (plasticized) & 9.19 & 62.0 & 721.9 \\
\hline
\end{tabular}

method was adopted for measuring the electrical conductivity at different frequencies.

\section{Characterization of CNTs/polymer matrix composites}

The synthesised CNTs/polymer matrix composites were yielded to a characterization process. Physical properties, such as mechanical and electrical properties, were measured for the nanocomposites under investigation. The results of the TGA analysis, the FTIR spectroscopy, and the SEM microscopy for the synthesized nanocomposites disclosing their intrinsic properties, functionalities, and morphologies are also presented and discussed in the following.

\subsection{Mechanical and physical properties}

Instron universal testing machine was employed to conduct tension tests on standard specimens made from both CNTs/PVC composite and PVC polymer alone. The results are tabulated in Table 1 . It can be observed that the existence of CNTs in the PVC polymer matrix has remarkably increased its elongation percent and in turn increased both ductility and toughness on the account of strength and modulus of elasticity. In other words, the existence of CNTs in the PVC polymer matrix has transformed the material from a plasticized nature to a resilient rubbery one.

The electrical conductivities of both CNTs/PVC and CNTs/PS nanocomposites were deduced from their resistances measured by the two probe-point method. Figures 1a, 1b depict the electrical conductivities of CNTs/PVC and CNTs/PS polymer matrix composites against the frequency of the applied AC current. Sharp
Table 2. TGA of CNTs/PVC composite.

\begin{tabular}{ccc}
\hline Weight loss \% & \multicolumn{2}{c}{ Degradation temperature ${ }^{\circ} \mathrm{C}$} \\
\cline { 2 - 3 } & Start & End \\
\hline 31.455 & 67.51 & 238.25 \\
33.526 & 237.29 & 338.38 \\
16.522 & 339.11 & 492.56 \\
83.189 & 27.51 & 500.72 \\
\hline
\end{tabular}

shootings in the electrical conductivity can be observed at high frequency range where the CNTs and other existing elements got functionalized. The measured resistance of CNTs/PVC matrix composite was found to decrease to $5.0 \times 10^{-8} \Omega$, which is equivalent to about five times increase in the electrical conductivity of the PVC polymer as shown in Figure 1a. A profound effect of CNTs can also be observed in Figure 1b for CNTs/PS nanocomposites where at two different frequencies, shooting in the conductivity can be observed. Compared with CNTs/PVC composite, different functionality groups seem to be responsible for those two shootings. In addition, this may be attributed to the difference in the water absorption percent of the $\mathrm{PVC}$ material which is less than $0.1 \%$, while it is more than $0.1 \%$ in the PS matrix material. The difference in the monomer structure and/or the polymerization chain structure of the two polymeric matrices causing difference in their electrical structures may also explain the exposed difference in their electrical conductivities [6].

\subsection{Thermal analysis}

Thermal analysis comprises a group of techniques in which a physical change in a substance is measured as a function of temperature, while the substance is subjected to a controlled temperature program. Thermogravimetric analysis (TGA) is a technique which relies on samples which decompose at elevated temperatures and monitors changes in the mass of the specimen on heating [7-9].

TGA is a quantitative technique where a sample is placed in a furnace on a sensitive balance and heated at a controlled rate of $10{ }^{\circ} \mathrm{C} / \mathrm{min}$. The furnace environment is also controlled by continuously purging the system with nitrogen. A characteristic curve is obtained displaying mass residue percent against temperature or time. Consequently, sample mass will decrease continuously until all the sample has burnt out giving a balance reading almost near to zero depending on any inorganic impurities that may be present. If CNTs/polymer matrix composites are concerned, the dispersed CNTs may be more thermally stable than the polymer matrix, thus burning at higher temperatures. The derivative of the relationship between the mass loss percent versus temperature can therefore be used during heating to identify any distinct peak assignable to materials or products in the composite as will be explained in the following.

\subsubsection{TGA of CNTs/PVC nanocomposites}

The TGA results for samples from CNTs/PVC nanocomposites are shown in Figure 2 and Table 2. It can be 


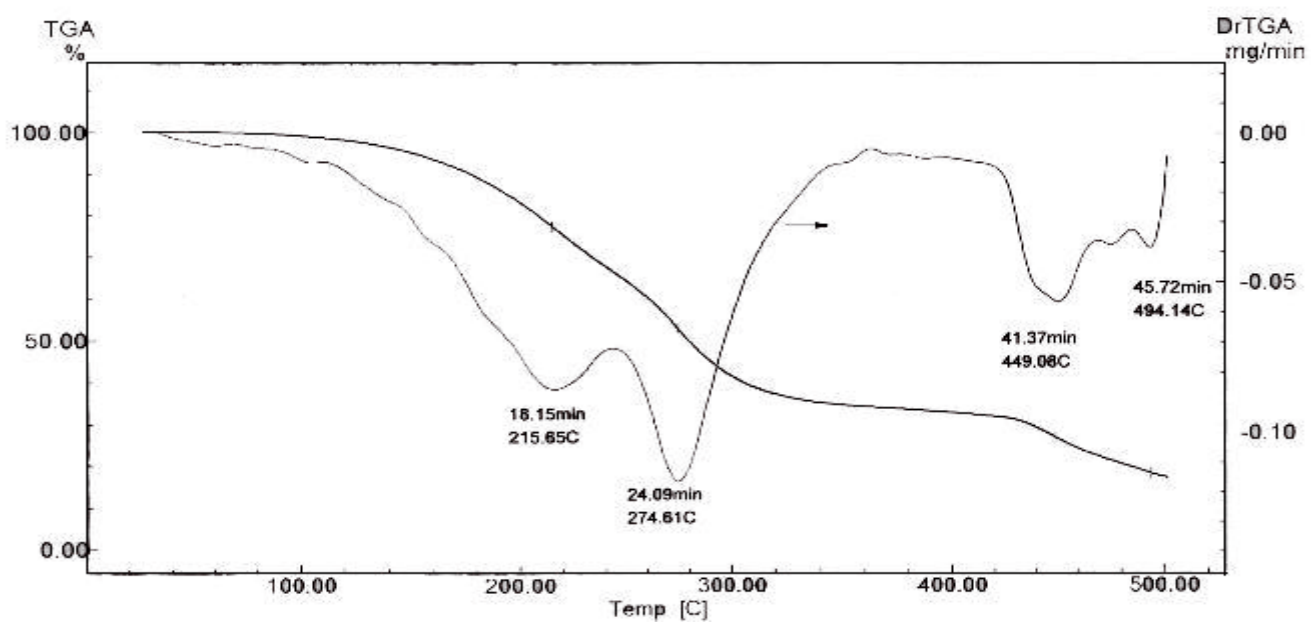

Fig. 2. TGA and its derivative (DrTGA) curves for CNTs/PVC composite.

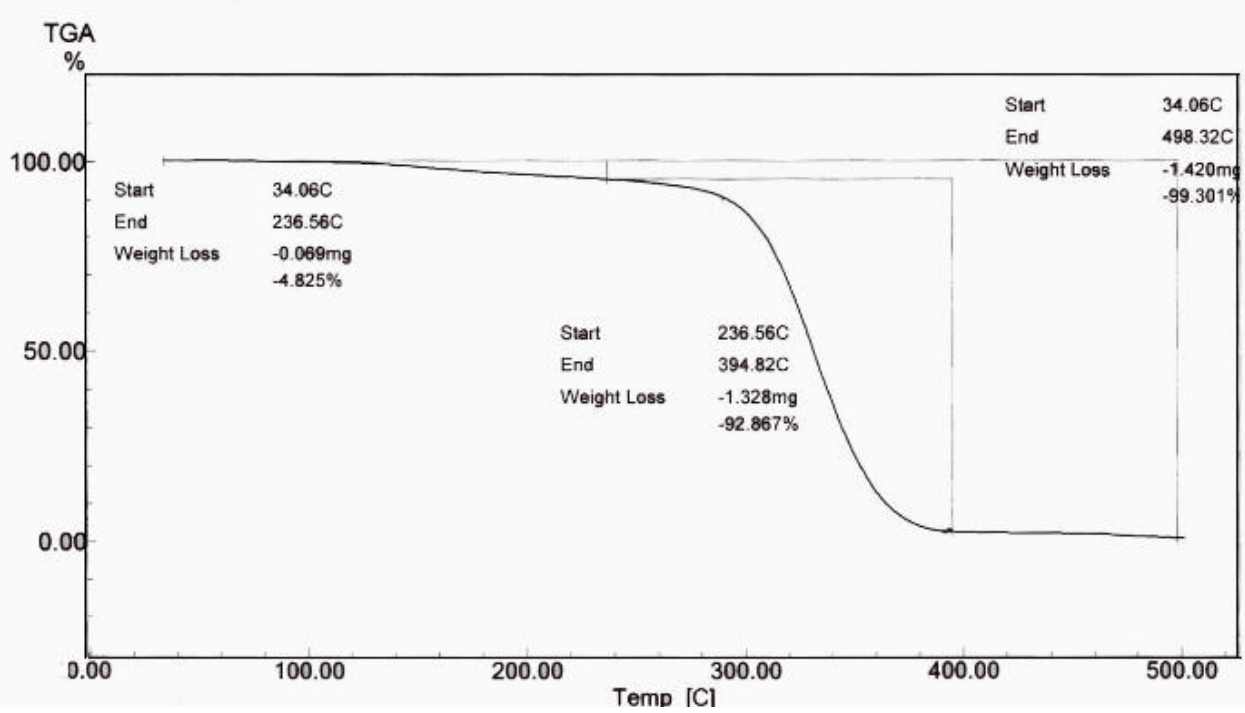

Fig. 3. TGA results of CNTs and CNTs/PMMA composite.

Table 3. TGA of PVC polymer [10].

\begin{tabular}{cc}
\hline Weight loss \% & Temperature ${ }^{\circ} \mathrm{C}$ \\
\hline $10 \%$ & 140 \\
$20 \%$ & 160 \\
$50 \%$ & 220 \\
$70 \%$ & 360 \\
$100 \%$ & 412 \\
\hline
\end{tabular}

observed that the composite could endure without burning until reaching $500{ }^{\circ} \mathrm{C}$ leaving almost $16.8 \%$ mass residue, while the PVC matrix material is completely degraded leaving no residue at $412{ }^{\circ} \mathrm{C}$ as shown in Table 3 which is recalled here just for comparison [10].

This indicates that the loaded CNTs have resulted in an increase in the thermal stability of the polymer matrix. It has been reported by the authors that the TGA results for samples of CNTs have revealed that they can sustain temperature rise up to almost $1000{ }^{\circ} \mathrm{C}$ [11]. 5 wt.\% CNTs doped in polymer matrix, though it is small percentile content, has resulted in an enhanced thermal stability of the composite. The gradient of the TGA curve shown in Figure 2 reveals four peaks at $215,274,449$, and $494{ }^{\circ} \mathrm{C}$. The first three peaks may represent the burning temperatures of the PVC and its functional groups of the associated crystalline and transformed amorphous polymers, while the fourth peak may represent the start of CNTs burning together with the possibly existing modifying inorganic filler materials.

\subsubsection{TGA of CNTs/PMMA nanocomposites}

TGA results of samples made from CNTs/PMMA Nanocomposites are shown in Figure 3. These results are also tabulated in Table 4 . Table 5 includes recalled data regarding TGA results for PMMA polymer which discloses that the sample material has burnt out completely at 
Table 4. TGA for CNTs/PMMA composite.

\begin{tabular}{ccc}
\hline Weight loss $\%$ & \multicolumn{2}{c}{ Degradation temperature ${ }^{\circ} \mathrm{C}$} \\
\cline { 2 - 3 } & start & end \\
\hline 4.825 & 34.06 & 236.56 \\
92.867 & 236.56 & 394.82 \\
99.301 & 34.06 & 498.32 \\
\hline
\end{tabular}

Table 5. TGA for PMMA polymer [10].

\begin{tabular}{cc}
\hline Weight loss $\%$ & Temperature ${ }^{\circ} \mathrm{C}$ \\
\hline $10 \%$ & 231 \\
$20 \%$ & 242 \\
$50 \%$ & 274 \\
$70 \%$ & 312 \\
$100 \%$ & 340 \\
\hline
\end{tabular}

Table 6. TGA of CNTs/PS composite.

\begin{tabular}{ccc}
\hline Weight loss $\%$ & \multicolumn{2}{c}{ Degradation temperature ${ }^{\circ} \mathrm{C}$} \\
\cline { 2 - 3 } & start & end \\
\hline 10.305 & 91.86 & 284.82 \\
82.622 & 284.82 & 429.38 \\
93.780 & 33.99 & 501.16 \\
\hline
\end{tabular}

$340{ }^{\circ} \mathrm{C}[10]$. However, the CNTs/PMMA composite could endure until reaching temperature of $500{ }^{\circ} \mathrm{C}$ leaving almost $0.7 \%$ mass residues, as shown in Table 4 . It can be confirmed once again that the CNTs loading in the polymer matrix has appreciably enhanced its thermal stability. The left over residues at reaching $500{ }^{\circ} \mathrm{C}$ can be explained by the fact that the carbon nanotubes together with other inorganic filler materials and/or possibly some polymer modifying additives may sustain temperatures more than $500{ }^{\circ} \mathrm{C}$. Thus, CNTs loading, even with a comparatively small percent, to the PMMA polymer matrix can enhance its thermal stability. The superimposed curve of the gradient of the TGA curve shown in Figure 3 reveals one clear peak at $331.75^{\circ} \mathrm{C}$ in addition to faint peaks at high ranges of temperatures. The strong clear sharp peak appeared at $331.75^{\circ} \mathrm{C}$ may represent the degradation temperature of the PMMA polymer matrix itself, whilst the other weak peaks noticed at higher temperature range between 400 and $500{ }^{\circ} \mathrm{C}$, may represent the degradation temperatures of the CNTs and probably the existing modifying filler materials as well.

\subsubsection{TGA of CNTs/PS nanocomposites}

TGA results of samples made from CNTs/PS nanocomposites are presented in Figure 4 and tabulated in Table 6. TGA results of PS polymer are recalled and presented in Table 7 for comparison [10]. It can be observed in Table 7 that at $360{ }^{\circ} \mathrm{C}$, the entire PS polymer sample has burnt out leaving no residues, while the composite could endure to a temperature of $501{ }^{\circ} \mathrm{C}$ leaving almost $6 \%$ mass residues as can be noticed in Table 6 . It can be also confirmed that the CNTs loading in the PS polymer matrix has increased its thermal stability. The same argument

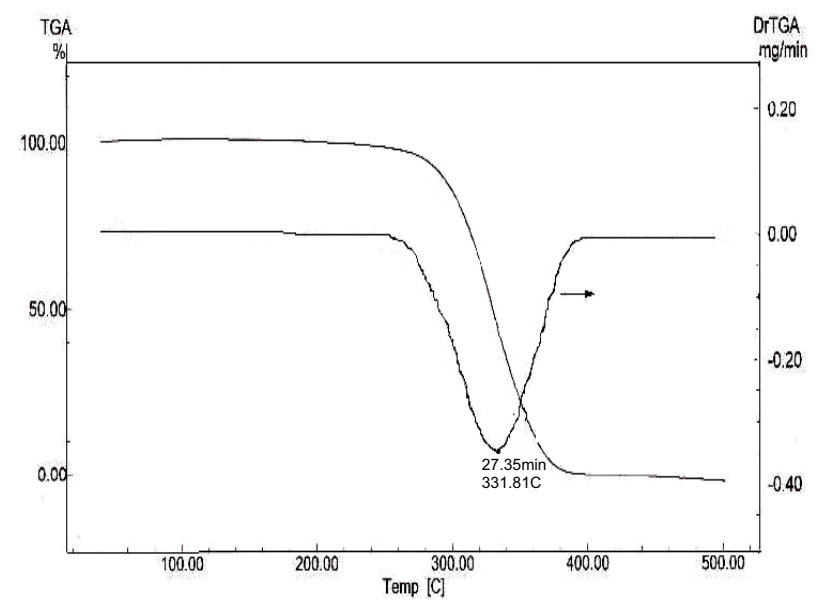

Fig. 4. TGA curve and its derivative for CNTs/PS composite.

Table 7. TGA of PS polymer [10].

\begin{tabular}{cc}
\hline Weight loss \% & Temperature ${ }^{\circ} \mathrm{C}$ \\
\hline $10 \%$ & 293 \\
$20 \%$ & 307 \\
$50 \%$ & 318 \\
$70 \%$ & 344 \\
$100 \%$ & 360 \\
\hline
\end{tabular}

can be used here to interpret the TGA results that showed $6 \%$ mass residues left over at $501{ }^{\circ} \mathrm{C}$. The gradient of the TGA curve shown in Figure 4 reveals one peak only at $331{ }^{\circ} \mathrm{C}$ which is a characteristic degradation temperature of the PS polymer itself while CNTs could endure up to the holding test temperature of $500{ }^{\circ} \mathrm{C}$.

\subsection{FTIR spectroscopy}

FTIR spectra were obtained for samples made from CNTs/polymer composites using Nexus apparatus (model-821, Medison, USA). CNTs were dispersed in the polymer using special optical tweezers and the resulted CNTs/polymer matrix composite was overlaid on a Potassium Bromide $(\mathrm{KBr})$ substrate to form a test disc that is suitable to be functionalized at wave number range from 400 to $4000 \mathrm{~cm}^{-1}$. A key has been used to interpret the results of the FTIR spectra and translate them into structurally and chemically implied functionalized groups upon exposing the composite samples to the infra red rays depending on the absorption frequency $[12,13]$.

\subsubsection{FTIR spectrum analysis of CNTs/PVC composites}

Fourier transform infra-red (FTIR) spectrum shown in Figure 5 is for CNTs/PVC composite. The spectrum discloses functionalized groups in the composite as it was exposed to IR. Fifteen peaks can be observed in Figure 5 pointing at the functional groups with the corresponding absorption frequency bandwidths. Table 8 presents these 


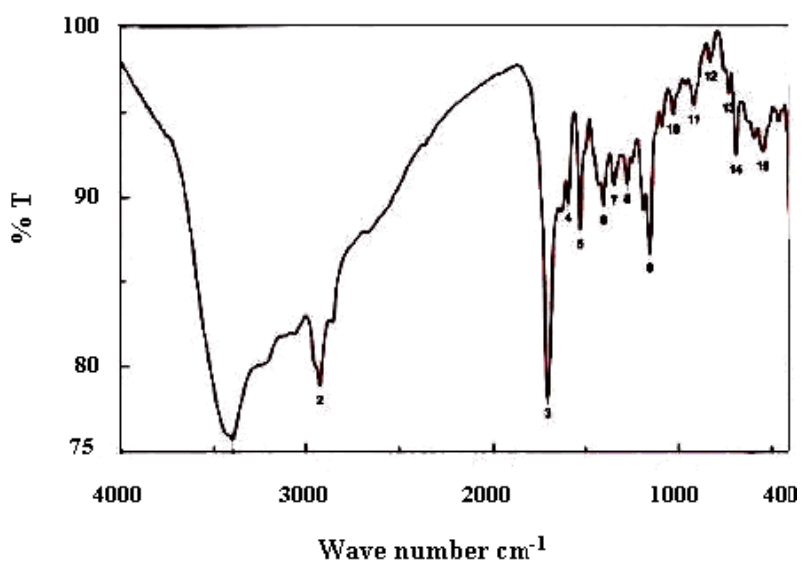

Fig. 5. FTIR spectrum of CNTs/PVC composite.

Table 8. FTIR characteristic functionality groups of CNTs/ PVC composite.

\begin{tabular}{ccccc}
\hline $\begin{array}{c}\text { Peak } \\
\text { No. }\end{array}$ & $\begin{array}{c}\text { Bands } \\
\mathrm{cm}^{-1}\end{array}$ & $\begin{array}{c}\text { Transmittance } \\
\%\end{array}$ & $\begin{array}{c}\text { Functional } \\
\text { group }\end{array}$ & Remarks \\
\hline 1 & 3399.00 & 75.70 & $\mathrm{~N}-\mathrm{H}$ (Bending) & $\mathrm{M}, \mathrm{Br}$ \\
2 & 2926.45 & 78.88 & $\mathrm{C}-\mathrm{H}$ (Stretch) & $\mathrm{S}, \mathrm{V}$ \\
3 & 1701.87 & 78.13 & $\mathrm{C}=\mathrm{O}$ (Stretch) & $\mathrm{S}, \mathrm{Sh}$ \\
4 & 1593.88 & 89.68 & $\mathrm{C}=\mathrm{C}$ (Stretch) & $\mathrm{W}$ \\
5 & 1531.20 & 88.15 & $\mathrm{C}=\mathrm{C}$ (Stretch) & $\mathrm{W}$ \\
6 & 1404.89 & 89.56 & $\mathrm{C}=\mathrm{H}$ (Bending) & $\mathrm{V}, \mathrm{Sh}$ \\
7 & 1349.93 & 90.72 & $\mathrm{NO}$ (Stretch) & $\mathrm{M}, \mathrm{W}$ \\
8 & 1279.54 & 90.79 & $\mathrm{~N}-\mathrm{H}$ (Bending) & $\mathrm{M}$ \\
9 & 1159.01 & 86.74 & $\mathrm{C}-\mathrm{O}$ (Stretch) & $\mathrm{M}, \mathrm{Br}$ \\
10 & 1033.66 & 94.85 & $\mathrm{C}-\mathrm{O}$ (Stretch) & $\mathrm{W}, \mathrm{V}$ \\
11 & 924.70 & 95.43 & $\mathrm{C}-\mathrm{H}$ (Stretch) & $\mathrm{W}, \mathrm{V}$ \\
12 & 836.00 & 97.96 & $\mathrm{C}-\mathrm{H}$ (Bending) & $\mathrm{W}, \mathrm{V}$ \\
13 & 736.67 & 96.1 & $\mathrm{C}-\mathrm{H}$ (Bending) & $\mathrm{W}$ \\
14 & 699.10 & 92.48 & $\mathrm{C}-\mathrm{H}$ (Bending) & $\mathrm{W}$ \\
15 & 550.60 & 92.68 & $\mathrm{C}-\mathrm{H}$ (Bending) & $\mathrm{W}, \mathrm{V}$ \\
\hline
\end{tabular}

- $\mathrm{V}=$ Variable, $\mathrm{M}=$ Medium, $\mathrm{S}=$ Strong, $\mathrm{Br}=\mathrm{Broad}, \mathrm{W}=\mathrm{Weak}$, and $\mathrm{Sh}=$ Sharp.

functional groups and the corresponding absorption bandwidths together with the transmittance percent representing the inverse of the importance and the intensity of the group.

\subsubsection{FTIR spectrum analysis of CNTs/PMMA composite}

FTIR spectrum of CNTs/PMMA composite shown in Figure 6 depicts the functionalized groups with the corresponding absorption frequency bandwidths and their relative characteristic intensities as described in Table 9.

Types of interfacial bonding between PMMA matrix and the CNTs demonstrated here could locally change the nature of the polymer relaxation mode.

\subsubsection{FTIR spectrum analysis of CNTs/PS composite}

FTIR spectrum shown in Figure 7 is for CNTs/PS polymer matrix composite. The spectrum displays thirty five

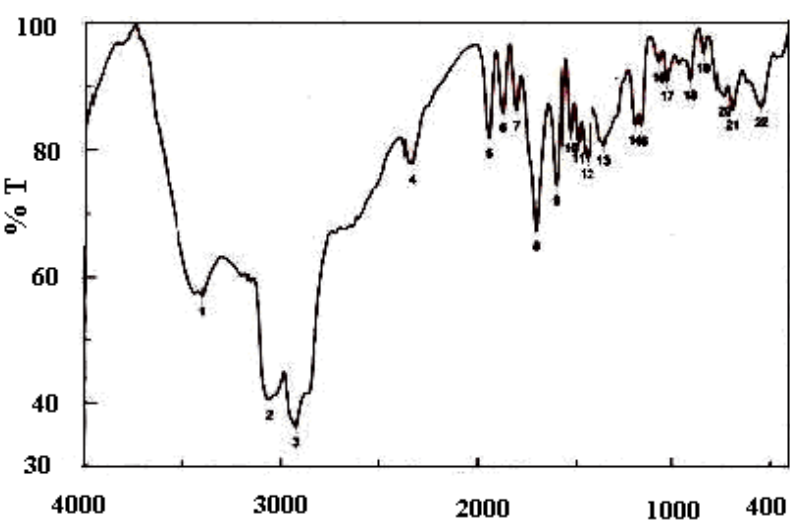

Fig. 6. FTIR spectrum of CNTs/PMMA composites.

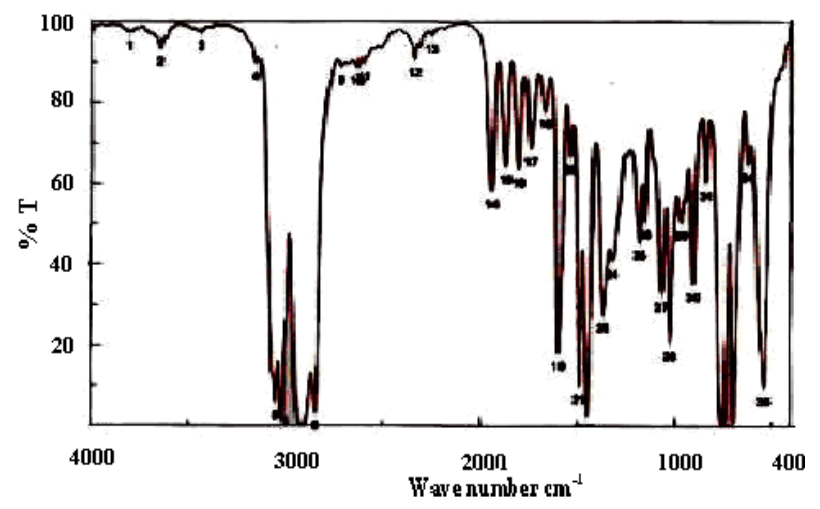

Fig. 7. FTIR spectrum of CNTs/PS composites.

Table 9. FTIR characteristic functionality groups of CNTs/ PMMA composite.

\begin{tabular}{ccccc}
\hline $\begin{array}{c}\text { Peak } \\
\text { No. }\end{array}$ & $\begin{array}{c}\text { Bands } \\
\mathrm{cm}^{-1}\end{array}$ & $\begin{array}{c}\text { Transmittance } \\
\%\end{array}$ & $\begin{array}{c}\text { Functional } \\
\text { group }\end{array}$ & Remarks \\
\hline 1 & 3398.92 & 57.09 & N-H (Stretch) & M \\
2 & 3061.44 & 40.52 & C-H (Stretch) & S, Br \\
3 & 2927.41 & 36.28 & C-H(Stretch) & S, Sh \\
4 & 2339.23 & 77.80 & C $\Xi$ C (Stretch) & W, Sh \\
5 & 1945.82 & 81.88 & C-H (Stretch) & W \\
6 & 1874.47 & 85.85 & C-H (Bending) & W \\
7 & 1804.08 & 86.13 & C-H (Stretch) & W \\
8 & 1701.87 & 67.34 & C=O (Stretch) & S \\
9 & 1596.77 & 74.53 & C=C (Stretch) & W \\
10 & 1533.13 & 82.71 & C=C (Stretch) & W \\
11 & 1493.60 & 81.09 & C-H (Bending) & V \\
12 & 1444.42 & 78.66 & C-H (Bending) & V \\
13 & 1354.75 & 80.75 & C-H (Bending) & V \\
14 & 1190.83 & 83.9 & C-O (Bending) & W, V \\
15 & 1159.01 & 83.74 & C-O (Bending) & W, V \\
16 & 1070.3 & 93.74 & C-O (Bending) & W, V \\
17 & 1026.91 & 90.83 & C-O (Bending) & W, V \\
18 & 908.308 & 90.97 & C-H (Bending) & W \\
19 & 840.812 & 95.26 & C-H (Bending) & W \\
20 & 740.531 & 88.46 & C-H (Bending) & W \\
21 & 699.069 & 86.28 & C-H (Bending) & W \\
22 & 546.72 & 86.75 & C-H (Bending) & W \\
\hline
\end{tabular}

- $\mathrm{V}=$ Variable, $\mathrm{M}=$ Medium, $\mathrm{S}=$ Strong, $\mathrm{Br}=$ Broad, $\mathrm{W}=$ Weak, and $\mathrm{Sh}=$ Sharp. 
Table 10. FTIR Characteristic functionality Groups of CNTs/ PS composite.

\begin{tabular}{|c|c|c|c|c|}
\hline $\begin{array}{l}\text { Peak } \\
\text { No. }\end{array}$ & $\begin{array}{l}\text { Bands } \\
\mathrm{cm}^{-1}\end{array}$ & $\begin{array}{c}\text { Transmittance } \\
\%\end{array}$ & $\begin{array}{l}\text { Functional } \\
\text { group }\end{array}$ & Remarks $^{\bullet}$ \\
\hline 1 & 3809.69 & 97.50 & $\mathrm{O}-\mathrm{H}$ (Stretch) & $\mathrm{W}, \mathrm{Br}$ \\
\hline 2 & 3647.70 & 93.56 & O-H (Stretch) & $\mathrm{W}, \mathrm{Br}$ \\
\hline 3 & 3442.31 & 97.50 & $\mathrm{~N}-\mathrm{H}($ Stretch $)$ & $\mathrm{W}, \mathrm{Br}$ \\
\hline 4 & 3158.83 & 89.94 & $\mathrm{O}-\mathrm{H}$ (Stretch) & $\mathrm{W}, \mathrm{Br}$ \\
\hline 5 & 5059.51 & 6.12 & $\mathrm{C}-\mathrm{H}$ (Stretch) & $\mathrm{S}$ \\
\hline 6 & 3025.76 & 1.44 & $\mathrm{C}-\mathrm{H}$ (Stretch) & $\mathrm{S}$ \\
\hline 7 & 2920.66 & 0.00 & C-H (Stretch) & $\mathrm{S}$ \\
\hline 8 & 2852.20 & 3.50 & $\mathrm{C}-\mathrm{H}$ (Stretch) & $\mathrm{S}$ \\
\hline 9 & 2723.96 & 88.98 & $\mathrm{C}-\mathrm{H}$ (Stretch) & M.V \\
\hline 10 & 2632.36 & 88.87 & $\mathrm{O}-\mathrm{H}$ (Stretch) & $\mathrm{Br}, \mathrm{W}$ \\
\hline 11 & 2602.47 & 89.87 & $\mathrm{O}-\mathrm{H}$ (Stretch) & $\mathrm{V}, \mathrm{Br}$ \\
\hline 12 & 2337.3 & 90.94 & $\mathrm{C} \Xi \mathrm{C}$ (Stretch) & $\mathrm{W}, \mathrm{Sh}$ \\
\hline 13 & 2255.34 & 96.66 & $\mathrm{C} \Xi \mathrm{C}$ (Stretch) & W, Sh \\
\hline 14 & 1943.89 & 58.36 & $\mathrm{C}-\mathrm{H}$ (stretch) & W, Sh \\
\hline 15 & 1872.54 & 64.38 & $\mathrm{C}-\mathrm{H}$ (stretch) & W, Sh \\
\hline 16 & 1803.12 & 63.55 & $\mathrm{C}-\mathrm{H}$ (stretch) & W, Sh \\
\hline 17 & 1743.33 & 68.84 & $\mathrm{C}-\mathrm{H}$ (stretch) & W, Sh \\
\hline 18 & 1668.12 & 78.15 & $\mathrm{C}=\mathrm{C}($ stretch $)$ & M \\
\hline 19 & 1599.66 & 18.16 & $\mathrm{~N}-\mathrm{H}$ (stretch) & $\mathrm{S}, \mathrm{Sh}$ \\
\hline 20 & 1540.85 & 66.87 & $\mathrm{~N}-\mathrm{H}$ (stretch) & $\mathrm{S}, \mathrm{Sh}$ \\
\hline 21 & 1491.67 & 9.98 & $\mathrm{C}=\mathrm{C}$ (stretch) & $\mathrm{S}, \mathrm{Sh}$ \\
\hline 22 & 1449.24 & 2.64 & $\mathrm{C}-\mathrm{H}$ (Bending) & $\mathrm{S}, \mathrm{Sh}$ \\
\hline 23 & 1372.1 & 27.76 & NO2 (stretch) & $\mathrm{S}$ \\
\hline 24 & 1323.89 & 41.04 & NO2 (stretch) & $\mathrm{S}$ \\
\hline 25 & 1185.04 & 45.59 & $\mathrm{C}-\mathrm{O}$ (stretch) & $\mathrm{M}, \mathrm{V}$ \\
\hline 26 & 1156.12 & 50.76 & $\mathrm{C}-\mathrm{O}$ (stretch) & $\mathrm{M}, \mathrm{Sh}$ \\
\hline 27 & 1069.33 & 32.89 & $\mathrm{C}-\mathrm{O}$ (stretch) & M, Sh \\
\hline 28 & 1026.91 & 20.73 & $\mathrm{C}-\mathrm{O}$ (stretch) & $\mathrm{S}, \mathrm{Sh}$ \\
\hline 29 & 966.162 & 50.55 & $\mathrm{C}-\mathrm{H}$ (Bending) & $\mathrm{W}, \mathrm{V}$ \\
\hline 30 & 907.344 & 35.34 & $\mathrm{C}-\mathrm{H}$ (stretch) & M, Sh \\
\hline 31 & 841.776 & 60.33 & $\mathrm{C}-\mathrm{H}$ (Bending) & $\mathrm{W}, \mathrm{Sh}$ \\
\hline 32 & 755.959 & 0.63 & $\mathrm{C}-\mathrm{H}$ (stretch) & S, Sh \\
\hline 33 & 700.033 & 0.9 & $\mathrm{C}-\mathrm{H}$ (Bending) & $\mathrm{S}, \mathrm{Sh}$ \\
\hline 34 & 622.895 & 64.93 & $\mathrm{C}-\mathrm{H}$ (Bending) & W, Sh \\
\hline 35 & 541.899 & 9.57 & $\mathrm{C}-\mathrm{H}$ (stretch) & $\mathrm{S}, \mathrm{Sh}$ \\
\hline
\end{tabular}

- $\mathrm{V}=$ Variable, $\mathrm{M}=$ Medium, $\mathrm{S}=$ Strong, $\mathrm{Br}=$ Broad, $\mathrm{W}=$ Weak, and $\mathrm{Sh}=$ Sharp.

peaks with the corresponding absorption bandwidths and peak shape description as summarized and tabulated in Table 10. These results confirm the role of CNTs during polymerization of PS.

\subsection{Morphological study}

Scanning electron microscopy (SEM) was used to study and characterize the synthesized CNTs/polymeric matrix composites (CNTs/PVC, CNTs/PMMA, and CNTs/PS).

Torn edge surface of the thin film sample of nanocomposites (using minimal cutting device at a rate of $0.2 \mathrm{~mm} / \mathrm{min}$ ) was prepared for SEM investigation. The following sections conclude the results and discussion of the SEM images using nanoscale metrology.

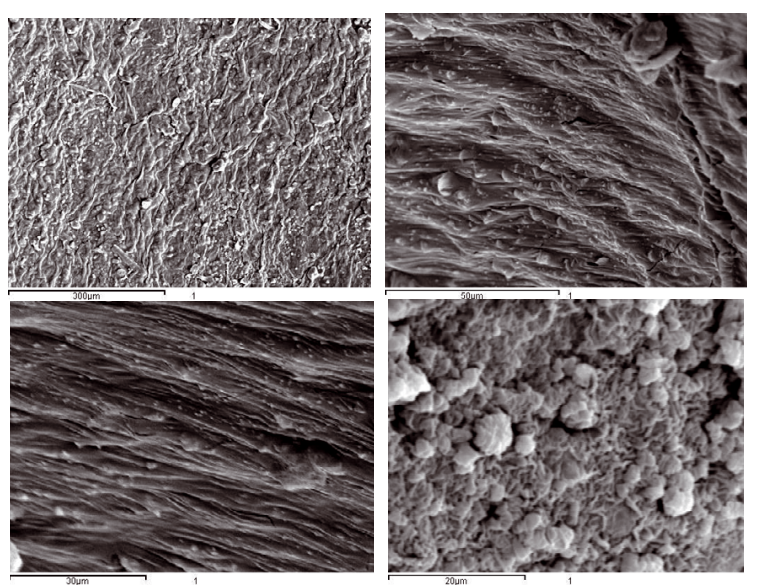

Fig. 8. SEM images for CNTs/PVC nanocomposites.
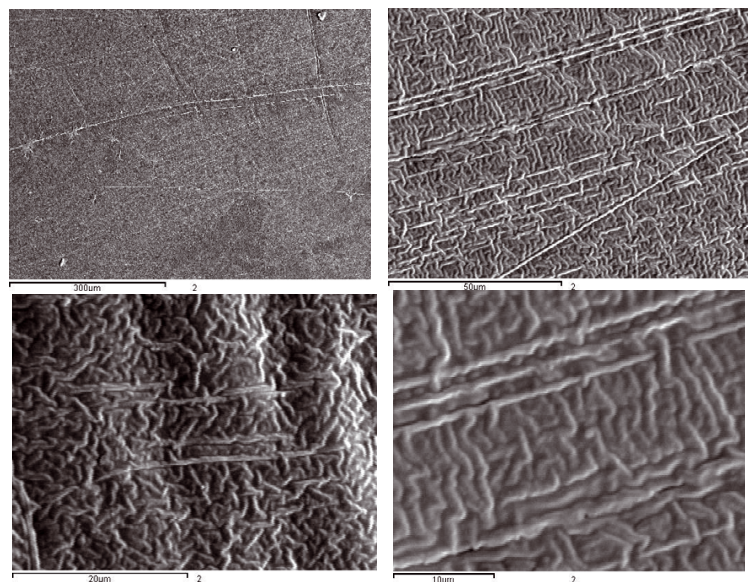

Fig. 9. SEM images for CNTs/PMMA nanocomposites.

\subsubsection{SEM images for CNTs/PVC nanocomposites}

Figure 8 illustrates SEM images for CNTs/PVC polymer matrix composites exposed with different magnifications. It can be observed that the cross-linking between the CNTs and the PVC matrix is relatively weak as separated clogs of polymer can be observed in the high resolution shots. This may be attributed to the passive electrical properties nature of the PVC as can be noticed in the electrical conductivity curve depicted in Figure 1a, for the CNTs/PVC composite unless it is exposed to high frequency.

\subsubsection{SEM images for CNTs/PMMA nanocomposites}

An indication of the nanotubes dispersion quality achieved is illustrated in Figure 9. Torn edge surface of the thin film sample of CNTs/PMMA composite (using minimal cutting device at shearing rate of $0.2 \mathrm{~mm} / \mathrm{min}$ at room temperature) was prepared for SEM investigation.

SEM images with different magnifications can be seen in Figure 9 in which clusters of CNTs with a few protruding bundles are disclosed. Meanwhile, it can also be noticed that the strong cross linking significantly improved 

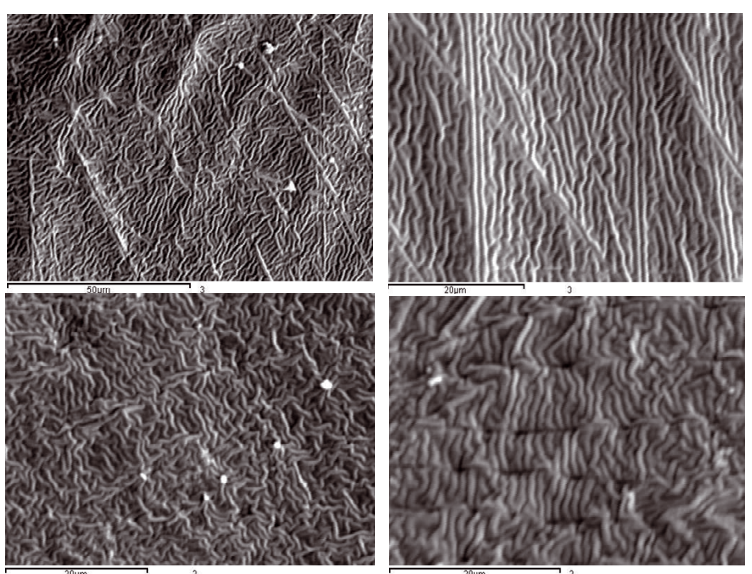

Fig. 10. SEM micrographs of CNTs/PS composites.

the CNTs dispersion throughout the PMMA matrix, thus forming good reinforcing network within the polymer. The high quality of achieved dispersion of the CNTs within the polymer matrix reflects favorably on the mechanical, electrical, and thermal properties of the composite.

\subsubsection{Scanning electron microscopy of CNTs/PS nanocomposite}

Figure 10 shows the SEM images of CNTs dispersion in PS polymer matrix composite. The apparently homogeneous dispersion and the strong interfacial bonding and cross linking between CNTs and PS polymer matrix is obvious. The functionalized knit-like interweave appearance indicates how CNTs play a role as a reinforcing agent in the PS matrix. It can be concluded that CNTs suit well the PS polymer matrix for synthesizing competent composite for different applications. The results of the thermal analysis of the CNTs/PS composites together with its FTIR spectrum discussed before, confirm this matching phenomenon of the CNTs and the PS polymer.

\section{Conclusions}

This work aims at using CNTs synthesized in lab by submerged DC arc discharge technique in tailoring polymer matrix nanocomposites having up to 5 wt.\% dispersed CNTs. Three polymers namely PVC, PMMA, and PS have been adopted throughout the experimentation. The three types of synthesized nanocomposites have been characterized by measuring their mechanical, electrical, and thermal properties. In addition, FTIR spectroscopy and SEM microscopy have been investigated using nanometrology techniques. The test results have been presented and discussed. It can be concluded that both PMMA and PS polymers experienced much better matching ability and cross linking ability with the interweaving CNTs than the PVC polymer. Thus, both PMMA and PS polymers may be nominated for further extension of the investigation to cover a wider range of CNTs content ratios in an endeavour towards searching for maximum specific performance properties of such nanocomposites.

\section{References}

1. M. Eijiro, Carbon Nanotube-Polymer Composite for Light-Driven Microthermal Control (Wiley-VCH Verlag GmbH \& Co. KGaA, Weinheim, 2008), Vol. 47, pp. 36103613

2. R. Martel, T. Schmidt, H.R. Shea, T. Hertel, Single and multi-wall carbon nanotube field-effect transistors, Appl. Phys. Lett. 3, 2447 (1998)

3. B. Sundaray, Preparation and Electrical Characterization of Electrospun Fibers of Carbon Nanotube-Polymer Nanocomposites, Ph.D. thesis, Dept of Physics, Indian Institute of Technology, Madras Chennai, India, 2006, www.physics.iitm.ac.in/research_files/synopsis/bibek.pdf

4. Salah H.R. Ali, M.A. Etman, B.S. Azam, M.K. Bedewy, Parametric study of CNTs production using submerged arc-discharge technique, in Proceeding of the CON008 Conference, Saudi Arabia (2008)

5. M.A. Etman, Synthesis and evaluation of carbon nanotubes and its applications in nanocomposites, Ph.D. thesis, Mech. Design \& Prod. Eng. Dept., Cairo Univ., 2008

6. H. Xu, S. Zhang, S.M. Anlage, L. Hu, G. Grüner, Frequency- and electric-field-dependent conductivity of single-walled carbon nanotube networks of varying density, The American Physical Society, Phys. Rev. B 77, 075418 (2008)

7. http://www.si-mex.com.mx

8. S.A. Endo, M.J. Hikosaka, Conditions for melt crystallization without thermal degradation and equilibrium melting temperature of atactic poly (vinyl alcohol), Macromol, Sci. Phys. Part B 42, 793 (2003)

9. J.W. Gillman, D.L. VanderHart, T. Kashiwagi, Thermal decomposition chemistry of poly (vinyl alcohol)', Fire and Polymers II: Materials and Test for Hazard Prevention ACS (1994), Vol. 599, p. 161

10. M.N. Ibrahim, Comparative studies of polymerization techniques for polymer nanocomposites synthesis for industrial applications, MSc thesis, Helwan University, Cairo, Egypt, 2007

11. Salah H.R. Ali, M.A. Etman, B.S. Azam, R.M. Rashed, M.K. Bedewy, Advanced Nanometrology Techniques for Carbon Nanotubes Characterization, J. Metrol. Meas. Syst. 15, 551 (2008)

12. http://www.als.lbl.gov

13. http://www.snake.irf.sa/optlab/ftir/index.html 